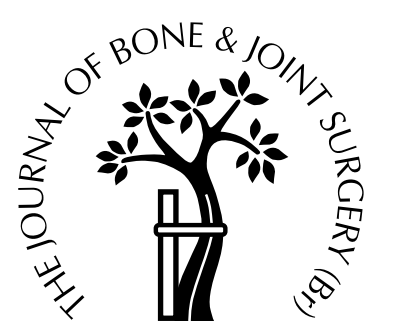

\title{
Femoral shortening in intertrochanteric fractures
}

\author{
A COMPARISON BETWEEN THE MEDOFF SLIDING \\ PLATE AND THE COMPRESSION HIP SCREW
}

\author{
O. Olsson, L. Ceder, A. Hauggaard \\ From Helsingborg Hospital, Helsingborg, Sweden
}

W e compared 54 patients treated by a Medoff sliding plate (MSP) with 60 stabilised by a compression hip screw (CHS) in a prospective, randomised study of the management of intertrochanteric femoral fractures. Four months after the operation femoral shortening was determined from radiographs of both femora.

In unstable fractures the mean femoral shortening was $15 \mathrm{~mm}$ with the MSP and $11 \mathrm{~mm}$ with the CHS ( $p=0.03$ ). A subgroup in which shortening was classified as large, comprising one-third of the patients in each group, had a similar extent of shortening, but more medialisation of the femoral shaft occurred in the CHS $(26 \%)$ than in the MSP $(12 \%)$ group $(p=0.03)$. Five postoperative failures of fixation occurred with the CHS and none with the MSP ( $p=0.03$ ). The marginally greater femoral shortening seen with the MSP compared with the CHS appeared to be justified by the improved control of impaction of the fracture. Biaxial dynamisation in unstable intertrochanteric fractures is a safe principle of treatment, which minimises the rate of postoperative failure of fixation.

J Bone Joint Surg [Br] 2001;83-B:572-8

Received 26 April 2000; Accepted after revision 21 November 2000

The Medoff sliding plate (MSP) was developed for the treatment of intertrochanteric and high subtrochanteric fractures in order to reduce the incidence of postoperative failure of fixation. ${ }^{1,2}$ The addition of a second sliding function along the axis of the femoral shaft was designed to provide optimal stress transmission over the area of the fracture and to facilitate impaction to a more stable config-

O. Olsson, MD, Consultant Orthopaedic Surgeon

L. Ceder, MD, Consultant Orthopaedic Surgeon

Department of Orthopaedics

A. Hauggaard, MD, Consultant Radiologist

Department of Radiology

Helsingborg HospitaL, S-251 87 Helsingborg, Sweden.

Correspondence should be sent to Dr O. Olsson.

(C)2001 British Editorial Society of Bone and Joint Surgery 0301-620X/01/411302\$2.00 uration. More efficient elimination of bone deficit in the comminuted region of the fracture may, however, result in increased femoral shortening compared with fixation by a sliding hip screw. We have therefore compared in a randomised study the MSP with the compression hip screw (CHS) by assessing the outcome of fracture fixation and the amount of femoral shortening in different types of intertrochanteric fracture.

\section{Patients and Methods}

The MSP (Medpac, Valencia, California) has a proximal barrel which accommodates the lag screw, similar to a standard sliding hip screw. The barrelled side plate has a sliding element and is attached to the femoral shaft by four converging screws (Fig. 1). A maximum slide of $25 \mathrm{~mm}$ along the axis of the femoral shaft is possible. There must be distal enlarging of the entry hole of the plate barrel, otherwise the latter will impinge on the intact lateral cortex and sliding of the plate will be prevented. We compared the MSP with a four-hole Richards classic CHS (Smith and Nephew, Memphis, Tennessee).

Between November 1998 and October 1999, all consecutive patients who sustained an intertrochanteric fracture of the hip were included in the study. We excluded patients who had had earlier surgery of the ipsilateral femur or who had pathological fractures. The study was approved by the Ethical Committee. After informed consent from the patient or from relatives if the patient suffered from dementia, randomisation was achieved by the drawing of an unseen card specifiying the method of fixation to be used. Three patients were excluded after randomisation, one with a combined cervical and intertrochanteric fracture, and two with combined inter- and subtrochanteric fractures. The operations were carried out by 22 surgeons, with 54 patients of mean age 84 years (62 to 98) receiving the MSP, and 60 of mean age 84 years (61 to 96) the CHS. Prophylactic anticoagulant therapy with subcutaneous Enoxaparin (40 mg daily) was begun before the operation and continued until the patient was mobilised. Intravenous antibiotic therapy (cefuroxime $1500 \mathrm{mg}$ ) was given intraoperatively with one subsequent dose after 24 hours. After operation all patients were allowed immediate weightbearing as tolerated. 


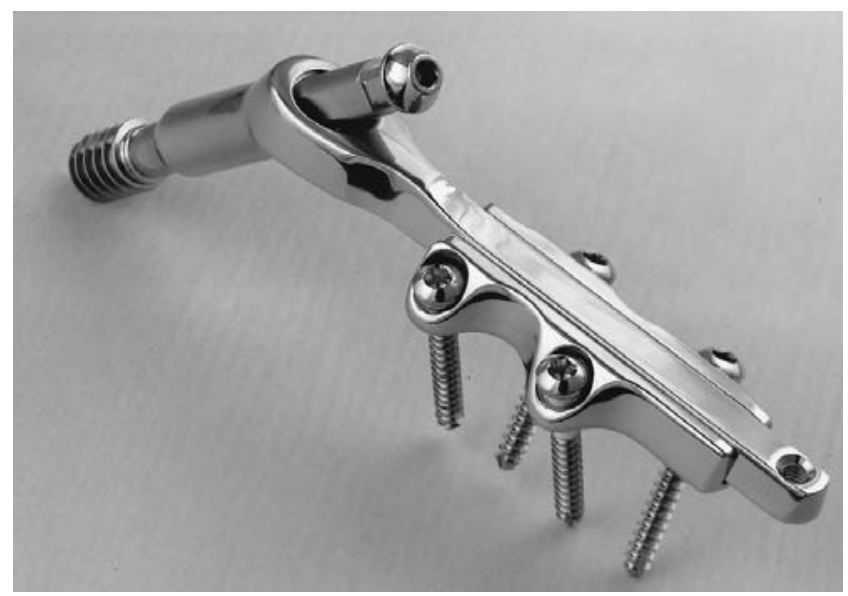

Fig. 1

The MSP with sliding capacity along both the axis of the femoral neck and along the femoral shaft. The sliding function along the femoral neck with the Medoff sliding plate and with the compression hip screw is similar.

The level of haemoglobin before and within three days of operation and the number of units of packed red cells given in this time were recorded. The operating time, intraoperative bleeding, any deep-venous thromboses as verified by phlebography, pulmonary embolism as verified by pulmonary scintigraphy and wound infections were also noted. Four months after the operation, the patients were assessed clinically and questioned about residential status and walking capacity.

Anteroposterior (AP) and lateral radiographs of the injured hip and an AP view of the pelvis were obtained. Radiological examinations of the hip were repeated postoperatively. At four months, radiographs of both femora, parallel in extension and parallel to the film cassette, were obtained. During all radiological examinations, efforts were made to keep the proximal femur in neutral rotation. The fractures were classified according to Jensen and Michael$\operatorname{sen}^{3}$ (Fig. 2). Type-III (lack of lateral support), type-IV (lack of medial support) and type-V (lack of lateral and medial support) fractures were considered to be unstable. The postoperative radiographs were evaluated for positioning of the device. Femoral shortening was determined by measuring the distance from the top of the femoral head to the centre of a line drawn between the most distal part of the medial and lateral femoral condyles. The uninjured contralateral femur was used as the control. In 19 patients the femoral length could not be determined on both sides because of a previous contralateral fracture of the hip, previous replacement of the hip or knee or inability of the patient to co-operate in the radiological examination with both legs in the parallel position. Instead, fixed reference points on the main proximal and distal fragments were used and compared with the contralateral hip on the initial pelvic radiograph. Estimations of the plate/barrel angle and the length of the barrel on the radiograph were used to assess femoral rotation on the postoperative and the four-month radiographs. Migration of the lag screw was estimated by dividing the femoral head into four quadrants by two perpendicular lines on both the AP and lateral views. The position of the tip of the device was then compared on the first postoperative and the four-month radiographs. Movement of $3 \mathrm{~mm}$ or more was considered to represent migration.

Medialisation of the femoral shaft was determined by measuring the femoral diameter at the level of the inferior aspect of the lesser trochanter, and was expressed as the fraction of overlapping of the proximal and distal medial cortices at the level of the fracture. Varus angulation was estimated by determining the angle between a line drawn through the centre of the femoral head and neck and a line parallel to the femoral shaft. The intact contralateral hip on the initial pelvic radiograph, or when available, previous radiographs of any of the hips, served as reference. If the contralateral hip was not intact or if the femoral rotation on the two sides was not considered to be similar, varus angulation could not be determined. An estimated reduction
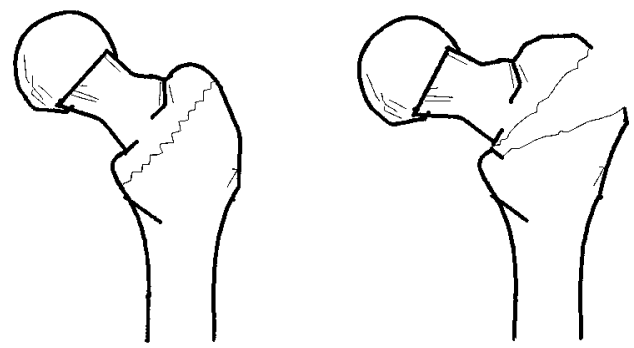

Type I

MSP: 0

CHS: 0

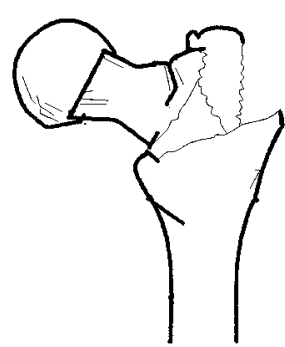

Type III

MSP: 13

CHS: 11

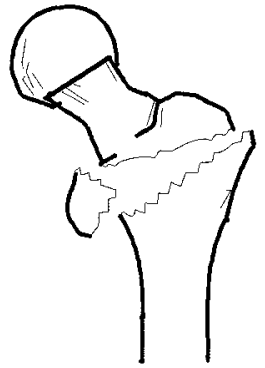

Type IV

MSP: 1

CHS: 2

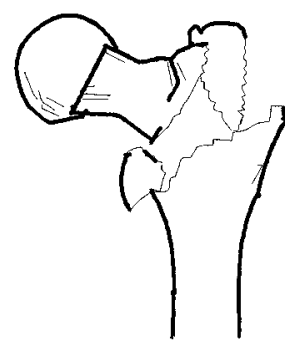

Type V

MSP: 35

CHS: 40

Fig. 2

The Jensen and Michaelsen ${ }^{3}$ classification of intertrochanteric fractures with the number of patients with the different fracture types in each study group. 
in the angle of greater than $5^{\circ}$ was considered to represent varus angulation.

For sliding of the lag screw, we measured the distance from the tip of the screw to the proximal end of its barrel on the postoperative and four-month radiographs. If the femoral rotation appeared to be different, adjustment was made by measuring the relative length of the barrel of the plate on the two radiographs. Sliding of the MSP plate was estimated by measuring the length of the protruding distal end of the sliding element on the four-month radiograph. Failures of fixation after operation, defined as superior cutout or penetration of the femoral head by the lag screw, or breakage or loosening of the implant, were recorded. Radiological assessment of femoral shortening, migration of the lag screw, medialisation of the femoral shaft and varus angulation was made on the final films before a secondary procedure if this was undertaken within four months of the primary operation. A correction for an estimated magnification of $15 \%$ was made for measurements on all radiographs. Repeated measurements of femoral length were made on the radiographs of ten patients, to assess interobserver variability.

A sample size of 120 patients was estimated as necessary to detect a difference of $30 \%$ of an expected mean femoral shortening of $12 \mathrm{~mm}$, assuming a standard deviation of $20 \%$ of an expected range of 0 to $30 \mathrm{~mm}(\alpha 0.05$, power $80 \%)$. The estimate of the number of patients needed compensated for the expected relationship between stable and unstable fractures, for an expected number of patients lost to follow-up, and for an expected exclusion of a few patients because of the altered initial and final classification of the fracture.

Baseline characteristics were compared between the two groups and the mean values and standard deviations calculated. Comparisons were made by Fisher's exact test or by the odds ratio with $95 \%$ confidence intervals for proportions and by the Mann-Whitney $U$ test for continuous variables. Normal distribution was assessed by the Kolmogorov-Smirnov goodness-of-fit procedure. A p value $<0.05$ was considered significant.

\section{Results}

The baseline characteristics of both groups were similar (Table I). Four months after the injury, 98 patients were alive and 90 of these had a complete radiological and clinical follow-up. The remaining eight patients were unable to attend because of poor general health. No deviations from the intended operative procedure were noted in either of the groups. The operating time was slightly longer (58 $v 55 \mathrm{~min}$ ) and the estimated intraoperative bleeding (225 v $200 \mathrm{ml}$ ) and the decrease in the level of haemoglobin within three days of surgery $(33 v 30 \mathrm{~g} / \mathrm{l})$ were marginally larger in the MSP than in the CHS group, but were not statistically significant (Table II). Both groups were similar in regard to the general postoperative complications, length of hospital stay and mortality, residential status and the need for a walking support after four months (Table II).

The mean femoral shortening was larger for unstable $(13 \mathrm{~mm})$ than for stable $(7 \mathrm{~mm})$ fractures $(\mathrm{p}=0.04)$. For stable fractures, there were no differences between the MSP and CHS groups, but for unstable fractures (Table III), the mean femoral shortening was $4 \mathrm{~mm}$ greater in the MSP than in the CHS group $(\mathrm{p}=0.03)$. For Jensen and Michaelsen type- $\mathrm{V}$ fractures, the mean femoral shortening was $5 \mathrm{~mm}$ more $(17 v 12 \mathrm{~mm})$ in the MSP than the CHS group ( $p=0.04)$. Comparisons of femoral shortening were also made including only patients in whom the complete bilateral femoral length had been measured. The differences between the MSP and CHS groups remained similar at the same level of significance. In the CHS group the distribution of femoral shortening was skewed, and a larger number of patients had a small degree of femoral shortening $(\mathrm{p}<0.01)$. No similar asymmetry was noted in the

Table I. Baseline characteristics of the 114 patients with intertrochanteric fractures randomly assigned to fixation by the MSP or the CHS. Mean values with SD and range are given for continuous variables

\begin{tabular}{lll}
\hline & MSP & CHS \\
\hline Number of patients & 54 & 60 \\
Female:male & $40: 14$ & $40: 20$ \\
Age (years) & $84(7.5 ; 62$ to 98$)$ & $84(7.3 ; 61$ to 96$)$ \\
Living in own home before injury & 35 & 40 \\
Independent walking before injury & 21 & 25 \\
Independence in activities of daily living before injury & 30 & 33 \\
History & & \\
$\quad$ Ischaemic or congestive heart disease & 13 & 17 \\
Cerebrovascular lesion & 8 & 5 \\
$\quad$ Diabetes mellitus & 14 & 4 \\
$\quad$ Dementia & 5 & 14 \\
Fracture & 49 & 7 \\
$\quad$ Stable & $119(14 ; 89$ to 167$)$ & 120 (15; 93 to 160) \\
Unstable & &
\end{tabular}


Table II. Median intraoperative and postoperative parameters for the 114 patients with intertrochanteric fractures

\begin{tabular}{|c|c|c|c|}
\hline & MSP & CHS & p value* \\
\hline Operating time in minutes (range) & $58(25$ to 130$)$ & $55(21$ to 115$)$ & 0.23 \\
\hline Hospital stay in days (range) $\dagger$ & $11(4$ to 31$)$ & 12 (4 to 39$)$ & 0.07 \\
\hline $\begin{array}{l}\text { Complications } \\
\text { Intraoperative bleeding in } \mathrm{ml} \text { (range) } \\
\text { Haemoglobin fall within } 3 \text { days in g/l (range) } \\
\text { Blood transfusion within } 3 \text { days in units of packed red cells (range) } \\
\text { Wound infection } \\
\text { Thromboembolism } \\
\text { Mortality at } 4 \text { months }\end{array}$ & $\begin{array}{l}225(50 \text { to } 1200) \\
33(0 \text { to } 62) \\
2(0 \text { to } 10) \\
0 \\
0 \\
6\end{array}$ & $\begin{array}{r}200(50 \text { to } 650) \\
30(2 \text { to } 75) \\
2(0 \text { to } 9) \\
2 \\
0 \\
10\end{array}$ & $\begin{array}{l}0.07 \\
0.79 \\
0.77\end{array}$ \\
\hline Number living in own home before injury at 4 months & $32 / 24$ & $36 / 25$ & \\
\hline Number of independent $\ddagger$ walkers before injury at 4 months & $21 / 5$ & $23 / 6$ & \\
\hline
\end{tabular}

* Mann-Whitney U test

$\dagger$ three patients in the MSP group and two in the CHS group died during the hospital stay

\$ only patients alive after four months included

Table III. Radiological analysis of the 79 unstable fractures with a four-month radiological follow-up

\begin{tabular}{|c|c|c|c|c|}
\hline & MSP & CHS & p value & Odds ratio $(95 \% \mathrm{CI})$ \\
\hline Number of patients & 39 & 40 & & \\
\hline Femoral shortening in mm (range) & $15(0$ to 28$)$ & $11(0$ to 40$)$ & $0.03 *$ & \\
\hline $\begin{array}{l}\text { Varus angulation }>5^{\circ} \\
\text { Number of patients } \\
\text { Percentage of patients (range) }\end{array}$ & $\begin{array}{l}18 \\
14(6 \text { to } 24)\end{array}$ & $\begin{array}{l}16 \dagger \\
14(6 \text { to } 38)\end{array}$ & & $1.3(0.53$ to 3.1$)$ \\
\hline
\end{tabular}

* Mann-Whitney U test

$\dagger 1$ patient was excluded from the CHS group, since varus angulation could not be estimated due to femoral rotation

\$ Fisher's exact test

MSP group. The occurrence of greater femoral shortening was similar in the two groups, with more than $15 \mathrm{~mm}$ in 17 patients in the MSP group and in 14 in the CHS group. For the one-third of patients with the most shortening in each group, the mean shortening was $26 \mathrm{~mm}$ in the MSP and $24 \mathrm{~mm}$ in the CHS group $(\mathrm{p}=0.27)$. The repeated measurements of the lengths of 20 femora of ten patients varied from 0 to $1 \mathrm{~mm}$.

Migration of the lag screw and medialisation of the femoral shaft occurred more often and was more pronounced in the CHS than in the MSP group in unstable fractures, but the difference was not statistically significant (Table III). For the one-third of patients with the most shortening, the mean medialisation was $12 \%$ for the MSP and $26 \%$ for the CHS group $(p=0.03)$ (Fig. 3). Medialisation of more than $30 \%$ occurred in nine patients in the CHS group, but in no patients in the MSP group ( $p=0.003)$. The occurrence and severity of varus angulation were similar in both groups (Table III). For the one-third of patients with the most shortening varus angulation was observed in ten patients in the CHS and in five in the MSP group $(\mathrm{p}=0.13)$.

Sliding of the lag screw was significantly greater in the CHS than in the MSP group in unstable fractures (Table III), but similar in stable fractures. Plate sliding in the MSP group was $10 \mathrm{~mm}$ for stable and $14 \mathrm{~mm}$ for unstable fractures $(\mathrm{p}=0.19)$.

Five postoperative failures of fixation occurred in unstable fractures treated by the CHS (Table IV), but in none with the MSP $(p=0.03)$. No divergence from the intended intraoperative procedure was documented for the five patients with postoperative failure of fixation.

\section{Discussion}

Intertrochanteric fractures occur in elderly people with poor bone quality, and most are comminuted and unstable. Since early mobilisation is mandatory, the methods of fixation chosen must allow immediate weight-bearing. Early experiences with rigid devices in the fixation of unstable 
Table IV. Details of five cases of postoperative failure of fixation. All were cut-outs occurring in Jensen and Michaelsen ${ }^{3}$ type-V fractures which had been fixed with the CHS

\begin{tabular}{|c|c|c|c|c|c|c|}
\hline Case & $\begin{array}{l}\text { Age } \\
(\mathbf{y r})\end{array}$ & Gender & $\begin{array}{l}\text { Varus } \\
\text { angulation } \\
\text { (degrees) }\end{array}$ & $\begin{array}{l}\text { Femoral shaft } \\
\text { medialisation } \\
(\%)\end{array}$ & Secondary procedure & Status at final outcome \\
\hline 1 & 91 & F & 38 & 50 & $\begin{array}{l}\text { No reoperation due to poor } \\
\text { general condition }\end{array}$ & $\begin{array}{l}\text { Threatening nonunion five months after the injury } \\
\text { Patient non-ambulatory }\end{array}$ \\
\hline 2 & 89 & $\mathrm{~F}$ & 29 & 5 & $\begin{array}{l}\text { No measures since patient } \\
\text { asymptomatic }\end{array}$ & $\begin{array}{l}\text { The fracture was healed eight months after the injury } \\
\text { Patient ambulating with a walker }\end{array}$ \\
\hline 3 & 86 & $\mathrm{~F}$ & 21 & 44 & $\begin{array}{l}\text { No reoperation due to poor } \\
\text { general condition }\end{array}$ & $\begin{array}{l}\text { The fracture appeared partly consolidated nine months after the injury } \\
\text { Patient non-ambulatory }\end{array}$ \\
\hline 4 & 85 & $\mathrm{~F}$ & 13 & 43 & $\begin{array}{l}\text { Early reoperation with hemiarthroplasty } \\
\text { Late Girdlestone procedure due to deep infection }\end{array}$ & Patient non-ambulatory seven months after the injury \\
\hline 5 & 85 & M & 20 & 6 & $\begin{array}{l}\text { Early reoperation with open rereduction } \\
\text { and fixation with the MSP } \\
\text { Late Girdlestone procedure due to deep infection }\end{array}$ & Patient non-ambulatory five months after the injury \\
\hline
\end{tabular}

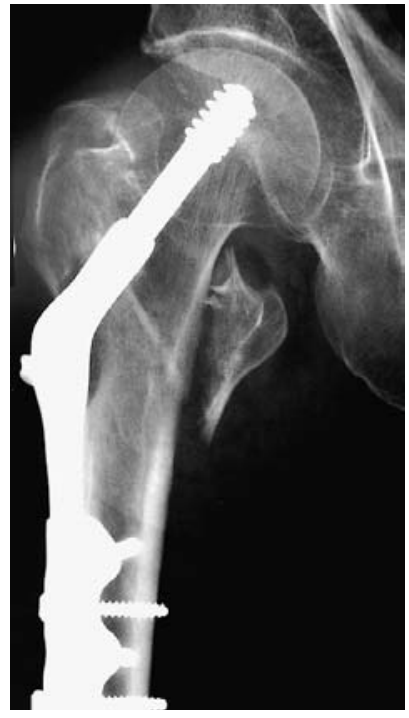

Fig. 3a

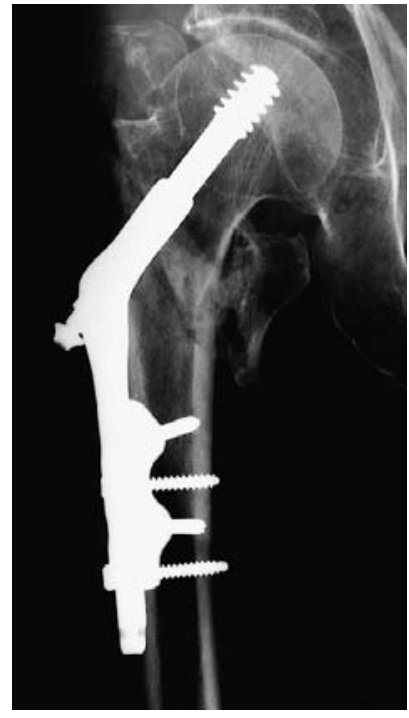

Fig. 3b

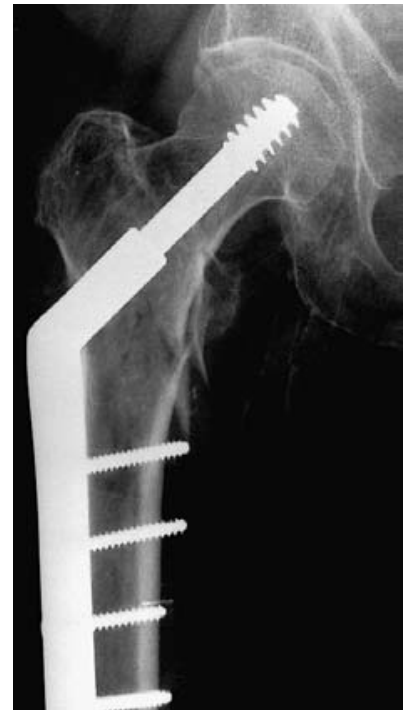

Fig. 3c

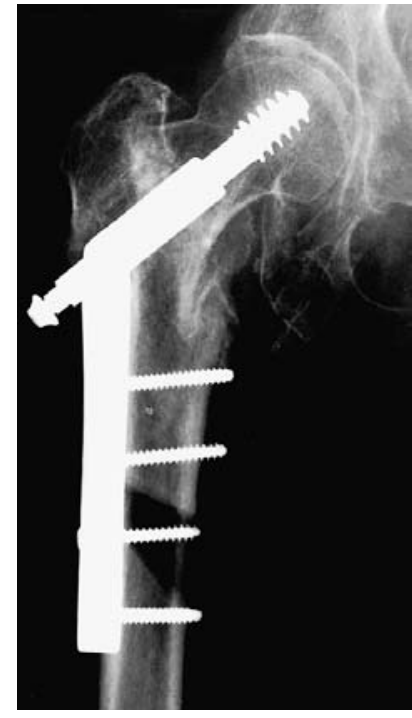

Fig. 3d

Fig. 3. Radiographs of two unstable Jensen and Michaelsen ${ }^{3}$ type-V intertrochanteric fractures postoperatively and after four months. With the MSP (a and $\mathrm{b}$ ), axial compression occurs with a resulting femoral shortening of $22 \mathrm{~mm}$, but with maintained alignment of the proximal and distal main fragments. With the CHS (c and d), a femoral shortening of $20 \mathrm{~mm}$ also occurs, but involving considerable medialisation of the femoral shaft.

intertrochanteric fractures confirmed that attempts to maintain anatomical position increased the risk of the failure of fixation if the device prevented secondary compression of the fracture. ${ }^{6,7} \mathrm{~A}$ bone defect in the region of the fracture cannot be protected by the implant, which is then subjected to high loads. ${ }^{8}$ Failures of fixation frequently follow uncontrolled impaction with migration of the implant or varus angulation because of bending or breakage of the device, or nonunion. With a sliding hip screw, stress transmission over the area of the fracture is improved, and the rate of failure of fixation is substantially decreased. ${ }^{6}$ The medial cortex is still, however, partially unloaded, ${ }^{9,10}$ and in prospective randomised studies, failure of fixation has occurred in $4 \%$ to $26 \%$ of cases. ${ }^{11-16}$

The direction of slide of the lag screw is usually $130^{\circ}$ to $140^{\circ}$ to the femoral shaft with a CHS. Depending on the geometry of the fracture, the efficacy of the impaction of the fracture provided by this mechanism may vary. It has been demonstrated that with a higher plate-to-barrel angle sliding is more effective, and that the sliding mechanism may be compromised if the lag screw is long relative to the length of the barrel. ${ }^{17}$ Biaxial dynamisation allowed by the MSP with concurrent impaction ability aligned $135^{\circ}$ and $180^{\circ}$ to the femoral shaft, was designed to address the postulated clinical and experimental disadvantages of a sliding hip screw. Biomechanical tests have confirmed that stress transmission is better with biaxial dynamisation than when dynamisation is restricted to the axis of the femoral neck. ${ }^{10,18}$ The rate of postoperative failure of fixation has been lower with the $\mathrm{MSP}^{2,19}$ than that generally reported with a sliding hip screw. This conclusion was also drawn in the only randomised study ${ }^{16}$ and we found a significantly lower rate of failure of fixation with the MSP compared with the CHS. There is now substantial evidence of the efficacy of the MSP in preventing failure of fixation after operation.

The influence of the facilitation of impaction of the main proximal and distal fragments on the subsequent femoral 
shortening has not previously been investigated. Our study showed that the mean excess shortening with the MSP compared with the CHS is marginally greater in unstable fractures. Pronounced femoral shortening was similar with both devices, but there was less medialisation of the femoral shaft with the MSP. A tendency for less migration and, in the most severe fractures, less varus angulation was also noted with the MSP. In the most unstable fractures, substantial impaction and shortening will occur irrespective of the method of fixation, but with biaxial dynamisation the process is more effectively controlled in terms of maintaining the alignment of the main proximal and distal fragments of the fracture. With the MSP, the sliding of the lag screw is partly replaced by sliding of the plate, which should involve less medialisation of the femoral shaft. Medialisation in excess of $30 \%$ implies a sevenfold increased risk of failure. ${ }^{20}$ Our observations also suggest that medialisation is an important factor in the mechanisms which cause failure of fixation.

The number of small femoral shortenings was larger in the CHS than in the MSP group, even for fractures classified as Jensen and Michaelsen type V. This suggests that some of the four-fragment fractures are stable enough to remain in the relative anatomical position when treated by the CHS, but the more effective impaction with the MSP produced moderate shortening. The classification system which we used did not identify inherently unstable fractures, and the stated consequences of medialisation of the femoral shaft suggest that the lateral support of the distal main fragment of the fracture may be a factor which is inadequately delineated by the Jensen and Michaelsen classification. Fractures which will impact substantially with a CHS have an increased risk of failure and would benefit from fixation with an MSP. On the other hand, fractures which would not impact appreciably with a CHS could have greater than necessary femoral shortening if treated with an MSP. It should be pointed out, however, that, apart from the stated arguments concerning secondary displacement of the fragments of the fracture, there is evidence to suggest that the consolidation process itself is enhanced by improved impaction. ${ }^{21}$

The slightly longer operating time and marginally larger intraoperative bleeding for the MSP was explained by having to enlarge the plate barrel entry hole distally in the lateral cortex. We have used both the MSP and CHS since 1992 and therefore all surgeons were equally experienced with both methods. Our data should be representative of the actual differences between the two methods.

The residential status and walking capacity were similar at four months, in both groups. The functional relevance of the small difference in femoral shortening is uncertain. Leg-length discrepancy of less than $30 \mathrm{~mm}$ has little effect on the biomechanical conditions of the hip ${ }^{22}$ and with leglength discrepancy of less than approximately $20 \mathrm{~mm}$, no compensatory strategies in walking pattern are observed. ${ }^{23}$ Most reports address treatment strategies for younger, otherwise healthy, patients, but there are few on the effects of post-traumatic leg-length discrepancy in the elderly. Gait disturbances are seen in all patients with a pronounced secondary collapse of the fracture with the sliding hip screw. ${ }^{24}$ In unstable intertrochanteric fractures, a mean femoral shortening of $16 \mathrm{~mm}$ with the sliding hip screw and $10 \mathrm{~mm}$ with an intramedullary hip screw, was reported ${ }^{25}$ and the latter group had higher mobility scores in the early postoperative period. Since a shoe-lift is a simple means of compensating for leg-length discrepancy when needed, the slightly larger mean femoral shortening with the MSP compared with the CHS, appears to be justified by the improved maintenance of alignment of the fracture and the reduction of the risk of failure of fixation. The prognosis for successful rehabilitation is poor when revision surgery is necessary after failure of fixation of a hip fracture. ${ }^{26}$ Two of the patients in our study demonstrated the potential magnitude of this problem with severe problems following failure of their fixation.

We chose follow-up at four months to maximise the number of patients available for radiological assessment of femoral shortening. With a later endpoint, the number of patients available would increase substantially, because of death and the difficulty of persuading some patients to attend. Several studies have shown that no further sliding with the MSP occurs after four months ${ }^{2,19,27}$ and, with a sliding hip screw, progressive shortening may take place for up to 16 weeks after the operation. ${ }^{28-30}$ Therefore, our chosen length of follow-up should allow for accurate estimate of the true femoral shortening. The incidence of nonunion could not be assessed in our patients.

We confirm that biaxial dynamisation in unstable intertrochanteric fractures is a safe principle of treatment which minimises the rate of postoperative failure of fixation. The marginally larger mean femoral shortening with the MSP compared with the CHS is justified by the improved control of the impaction of the fracture and by the lessened risk of postoperative failure of fixation. Future studies should focus on functional outcome with the MSP compared with other methods, and on improved methods of classification to identify the fractures at risk of severe secondary impaction, thereby giving a guide to the most appropriate method of fixation.

This study was supported by grants from the Stig and Ragna Gorthon Foundation and the Thelma Zoega Foundation, Helsingborg, and from the clinical research foundation of Malmöhus County Council, Lund.

No benefits in any form have been received or will be received from a commercial party related directly or indirectly to the subject of this article.

\section{References}

1. Medoff RJ, Maes K. A new device for the fixation of unstable pertrochanteric fractures of the hip. J Bone Joint Surg [Am] 1991;73-A:1192-9.

2. Olsson O, Ceder L, Lunsjö K, Hauggaard A. Biaxial dynamization in unstable intertrochanteric fractures: good experience with a simplified Medoff sliding plate in 94 patients. Acta Orthop Scand 1997;68:327-31. 
3. Jensen JS, Michaelsen M. Trochanteric femoral fractures treated with McLaughlin osteosynthesis. Acta Orthop Scand 1975;46:795-803.

4. Obrant KJ, Bengner U, Johnell O, Nilsson BE, Sembo I. Increasing age-adjusted risk of fragility fractures: a sign of increasing osteoporosis in successive generations? Calcif Tissue Int 1989;44:157-67.

5. Larsson S, Friberg S, Hansson L-I. Trochanteric fractures: mobility, complications and mortality in 607 cases treated with the sliding screw technique. Clin Orthop 1990;260:232-41.

6. Jacobs RR, Armstrong HJ, Whitaker HJ, Pazell J. Treatment of intertrochanteric hip fractures with a compression hip screw and a nail plate. J Trauma 1976;16:599-603.

7. Jensen JS, Sonne-Holm SS, Tondevold E. Unstable trochanteric fractures: a comparative analysis of four methods of internal fixation. Acta Orthop Scand 1980;51:949-62.

8. Kaufer H. Mechanics of the treatment of hip injuries. Clin Orthop 1980;146:53-61.

9. Mahomed N, Harrington I, Kellam J, et al. Biomechanical analysis of the Gamma nail and sliding hip screw. Clin Orthop 1994;304:280-8.

10. Olsson O, Kummer FJ, Ceder L, et al. The Medoff sliding plate and a standard sliding hip screw for unstable intertrochanteric fractures: a mechanical comparison in cadaver femurs. Acta Orthop Scand 1998;69:266-72.

11. Davis TRC, Sher JL, Horsman A, et al. Intertrochanteric femoral fractures: mechanical failure after internal fixation. J Bone Joint Surg [Br] 1990;72-B:26-31.

12. Nungu S, Olerud C, Rehnberg L. Treatment of intertrochanteric fractures: comparison of Ender nails and sliding screw plates. $J$ Orthop Trauma 1991;5:452-7.

13. Leung KS, So WS, Shen WY, Hui PQ. Gamma nails and dynamic hip screws for peritrochanteric fractures: a randomised prospective study in elderly patients. J Bone Joint Surg [Br] 1992;74-B:345-51.

14. Barrios C, Broström LA, Stark A, Walheim G. Healing complications after internal fixation of trochanteric hip fractures: the prognostic value of osteoporosis. J Orthop Trauma 1993;7:438-42.

15. Buciuto $\mathbf{R}$, Uhlin B, Hammerby $\mathbf{S}$, Hammer R. RAB-plate vs Richards CHS plate for unstable trochanteric hip fractures: a randomised study of 233 patients with 1-year follow-up. Acta Orthop Scand 1998;69:25-8.

16. Watson JT, Moed BR, Cramer KE, Karges DE. Comparison of the compression hip screw with the Medoff sliding plate for intertrochanteric fractures. Clin Orthop 1998;348:79-86.
17. Kyle RF, Wright TM, Burstein AH. Biomechanical analysis of the sliding characteristics of compression hip screws. J Bone Joint Surg [Am] 1980;62-A:1308-14.

18. Mahomed MN, Harrington IJ, Hearn TC. Biomechanical analysis of the Medoff sliding plate. $J$ Trauma 2000;48:93-100.

19. Lunsjö K, Ceder L, Stigsson L, Hauggaard A. Two-way compression along the shaft and the neck of the femur with the Medoff sliding plate: one-year follow-up of 108 intertrochanteric fractures. $J$ Bone Joint Surg [Br] 1996;78-B:387-90.

20. Parker MJ. Trochanteric hip fractures: fixation failure commoner with femoral medialization, a comparison of 101 cases. Acta Orthop Scand 1996;67:329-32.

21. Goodship AE, Kenwright J. The influence of induced micromovement upon the healing of experimental tibial fractures. $J$ Bone Joint Surg [Br] 1985;67-B:650-5.

22. McCaw ST, Bates BT. Biomechanical implications of mild leg length inequality. Br J Sports Med 1991;25:10-3.

23. Song KM, Halliday SE, Little DG. The effect of limb-length discrepancy on gait. J Bone Joint Surg [Am] 1997;79-A:1690-8.

24. Bendo JA, Weiner LS, Strauss E, Yang E. Collapse of intertrochanteric hip fractures fixed with sliding screws. Orthop Rev 1994;20-7.

25. Hardy DC, Descamps PY, Krallis P, et al. Use of an intramedullary hip-screw compared with a compression hip-screw with a plate for intertrochanteric femoral fractures: a prospective, randomized study of one hundred patients. J Bone Joint Surg [Am] 1998;80-A:618-30.

26. Keating JF, Robinson CM, Court-Brown CM, McQueen MM, Christie J. The effect of complications after hip fracture on rehabilitation. J Bone Joint Surg [Br] 1993;75-B:976.

27. Lunsjö K, Ceder L, Stigsson L, Hauggaard A. One-way compression along the femoral shaft with the Medoff sliding plate: the first European experience of 104 intertrochanteric fractures with a 1-year follow-up. Acta Orthop Scand 1995;66:343-6.

28. Yoshimine F, Latta LL, Milne EL. Sliding characteristics of compression hip screws in the intertrochanteric fracture: a clinical study. $J$ Orthop Trauma 1993;7:348-53.

29. Nakata K, Ohzono K, Hiroshima K, Toge K. Serial change of sliding in intertrochanteric femoral fractures treated with sliding screw system. Arch Orthop Trauma Surg 1994;113:276-80.

30. Hoffman CW, Lynskey TG. Intertrochanteric fractures of the femur: a randomized prospective comparison of the Gamma nail and the Ambi hip screw. Aust N Z J Surg 1996;66:151-5. 